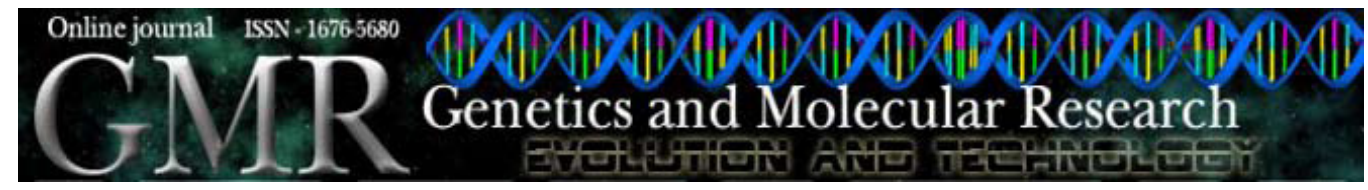

\title{
Genetic variability and heterogeneity of Venezuelan equine encephalitis virus vector Ochlerotatus taeniorhynchus (Diptera: Culicidae) populations of the Colombian Atlantic coast, based on microsatellite loci
}

\author{
F. Bello ${ }^{1}$ and V. Becerra ${ }^{2}$ \\ ${ }^{1}$ Faculty of Natural and Mathematical Sciences, \\ Universidad del Rosario, Bogotá, D.C., Colombia \\ ${ }^{2}$ Department of Basic Sciences, Universidad de la Salle, \\ Bogotá, D.C., Colombia
}

Corresponding author: F. Bello

E-mail: fbello@urosario.edu.co

Genet. Mol. Res. 8 (3): 1179-1190 (2009)

Received July 7, 2009

Accepted August 5, 2009

Published September 29, 2009

\begin{abstract}
In Colombia, the mosquito Ochlerotatus taeniorhynchus has been identified as an efficient vector of the epidemic-epizootic Venezuelan equine encephalitis virus. We evaluated the genetic variability and heterogeneity of this mosquito in Colombian populations using eight microsatellite DNA loci. Two hundred and ten mosquito specimens collected from seven populations of the Colombian Atlantic coast (San Bernardo del Viento, Coveñas, Cartagena, Barranquilla, Ciénaga, Dibulla, and Riohacha) were analyzed. We found five polymorphic microsatellite loci, with 19 alleles giving $62.5 \%$ polymorphism; the mean number of alleles per locus was 3.8. The mean expected heterogeneity ranged from 0.568 to 0.660 . Most of the polymorphic microsatellite loci were in Hardy-Weinberg disequilibrium, due to both deficit and excess of heterozygotes.
\end{abstract}


The Fst statistic gave a total value of 0.0369 , reflecting low genetic differentiation among the populations and, as a consequence, a low degree of structuring among them, while gene flow was high $(\mathrm{Nm}=6.52)$; these findings point to genetic homogeneity among these populations. There was no significant linkage disequilibrium between genotype pairs of the various populations. We concluded that this mosquito is distributed in local populations along the Colombian Atlantic coast; these findings will be useful for developing strategies for controlling this vector.

Key words: Ochlerotatus taeniorhynchus; Genetic heterogeneity; Venezuelan equine encephalitis virus; Polymorphic microsatellite loci; Genetic variability

\section{INTRODUCTION}

Ochlerotatus taeniorhynchus (Wiedemann) (Diptera: Culicidae) is an important mosquito in human and veterinary medicine because it is an efficient vector of Venezuelan equine encephalitis virus (VEEV) (Forattini, 1965; Ortiz and Weaver, 2004). Also, in the United States, this mosquito has been incriminated as the vector of the eastern equine encephalitis virus (Ortiz et al., 2003) and as potential vector of West Nile encephalitis (Hribar et al., 2003). This insect has a wide geographical distribution on the American continent particularly along the coasts; on the Atlantic coast, it is distributed from Massachusetts in the United States to Santa Catarina in south Brazil, and on the Pacific coast from California to Peru (Forattini, 1965). In Colombia, the mosquito has been found on both coasts (Atlantic and Pacific); it has also been detected inland in Ambalema, Department of Tolima (Olano, 1985). Nevertheless, there is no current evidence of its presence in the latter site (Laboratory of Medical Entomology, Universidad del Rosario).

In Colombia, periodic human epidemics and re-emerging equine epizooties of VEEV have occurred since 1938 (Dickerman et al., 1986). The last report of an epidemic-epizootic outbreak was in 1995, in the Colombian-Venezuelan Guajira region, during which 75,000 to 100,000 human cases were reported, 3000 with neurological complications and 300 fatal cases (Rivas et al., 1997). The species O. taeniorhynchus was recorded as one of the most abundant insects in the zone, which by epidemiological evidence, virus isolation and sensitivity tests at the laboratory level was incriminated in the transmission of the above-mentioned disease (Ortiz and Weaver, 2004).

Population genetic studies of vector mosquitoes were initiated by Craig and Hickey (1965) in the early 1960s in populations of Aedes aegypti, mainly using morphological characteristics. Since then, a great number of investigations have been conducted on the genetic variability and heterogeneity of several species of mosquitoes that are important to public health, using biochemical and molecular markers (Tabachnick and Black IV, 1996). Through the studies carried out, it has been possible to determine that the variation in vector competence among different mosquito populations is genetically determined (Aitken et al., 1977), thus making it possible to establish intraspecific polymorphisms in various complexes of these insects. Likewise, the knowledge of geographical patterns of 
genetic variability has provided "markers" for identifying possible biotypes or subspecies and their relations with ecological and behavioral factors, and other attributes of epidemiological importance (De Sousa et al., 2000). In general, the research on the genetics of populations of vector mosquitoes has been applied to: a) the determination of different taxonomic statuses among the species and, consequently, as support in defining the vector role of each species in the transmission of pathogenic agents; b) the evaluation of intraand interspecific genetic variability, and the estimation of the abilities to adapt to selective pressures, and c) the determination of gene flow among populations for the purpose of estimating the degree of isolation and gene circulation, especially in the resistant ones (Manguin et al., 1999).

Microsatellites are short chains of DNA formed by repeated sequences of 1 to 6 nucleotides (Schlotterer, 2000) characterized as markers of co-dominant expression, highly polymorphic, widely distributed in the genome and usually neutral (Hancock, 1999). Microsatellites have been used as genetic markers in studies on a wide range of insect disease vectors (Chambers et al., 2007). Particularly in mosquitoes, they have been extensively applied to different species of the genus Anopheles, for conducting population genetic studies (Ayala et al., 2006). Nevertheless, little research has been carried out with these markers in species of mosquitoes belonging to the subfamily Culicinae, except for various population genetic investigations carried out during the last years on the mosquito A. aegypti. However, a limited number of microsatellite loci have been used in this species (Chambers et al., 2007).

We previously carried out a study on the isoenzyme polymorphism and genetic structure of O. taeniorhynchus in populations from the Colombian Atlantic coast (Bello and RuizGarcia, 2009), which demonstrated relatively high levels of genetic variability with low values of genetic heterogeneity and high gene flow. In this report, we describe, for the first time, the use of eight microsatellite markers to analyze the genetic variability and heterogeneity of this mosquito from the same Colombian populations.

\section{MATERIAL AND METHODS}

\section{Populations analyzed and samples}

A total of 210 adult mosquitoes of $O$. taeniorhynchus were collected in the peripheral zones of seven different sites on the Colombian Atlantic coast. The following are the number of specimens and the populations sampled: 30 individuals from San Bernardo del Viento-Córdoba $\left(9^{\circ} 22^{\prime} 22^{\prime \prime} \mathrm{N}\right.$ and $\left.75^{\circ} 34^{\prime} 55^{\prime} \mathrm{W}\right), 30$ from Coveñas-Sucre $\left(9^{\circ} 31^{\prime} 41^{\prime \prime}\right.$ $\mathrm{N}$ and $\left.75^{\circ} 34^{\prime} 55^{\prime \prime} \mathrm{W}\right), 30$ from Cartagena-Bolívar $\left(10^{\circ} 23^{\prime} 59^{\prime \prime} \mathrm{N}\right.$ and $\left.75^{\circ} 30^{\prime} 52^{\prime \prime} \mathrm{W}\right), 30$ from Barranquilla-Atlántico $\left(10^{\circ} 57^{\prime} 42^{\prime \prime} \mathrm{N}\right.$ and $\left.74^{\circ} 46^{\prime} 54^{\prime \prime} \mathrm{W}\right), 30$ from Ciénaga-Magdalena $\left(11^{\circ} 00{ }^{\prime} 34^{\prime \prime} \mathrm{N}\right.$ and $\left.74^{\circ} 15^{\prime} 15^{\prime} \mathrm{W}\right), 30$ from Dibulla-Guajira $\left(11^{\circ} 17^{\prime} 00^{\prime} \mathrm{N}\right.$ and

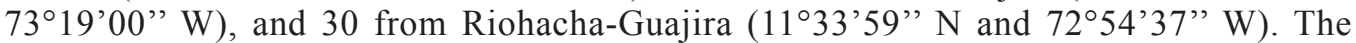
locations of the sites are shown in Figure 1. Collection of biological material was first carried out during the months of October, November and December 2005, and then again in the months of May, June and July 2006. Mosquitoes, maintained frozen in liquid nitrogen, were identified in the laboratory based on external morphological characteristics, using the taxonomic keys of Forattini (1965). 


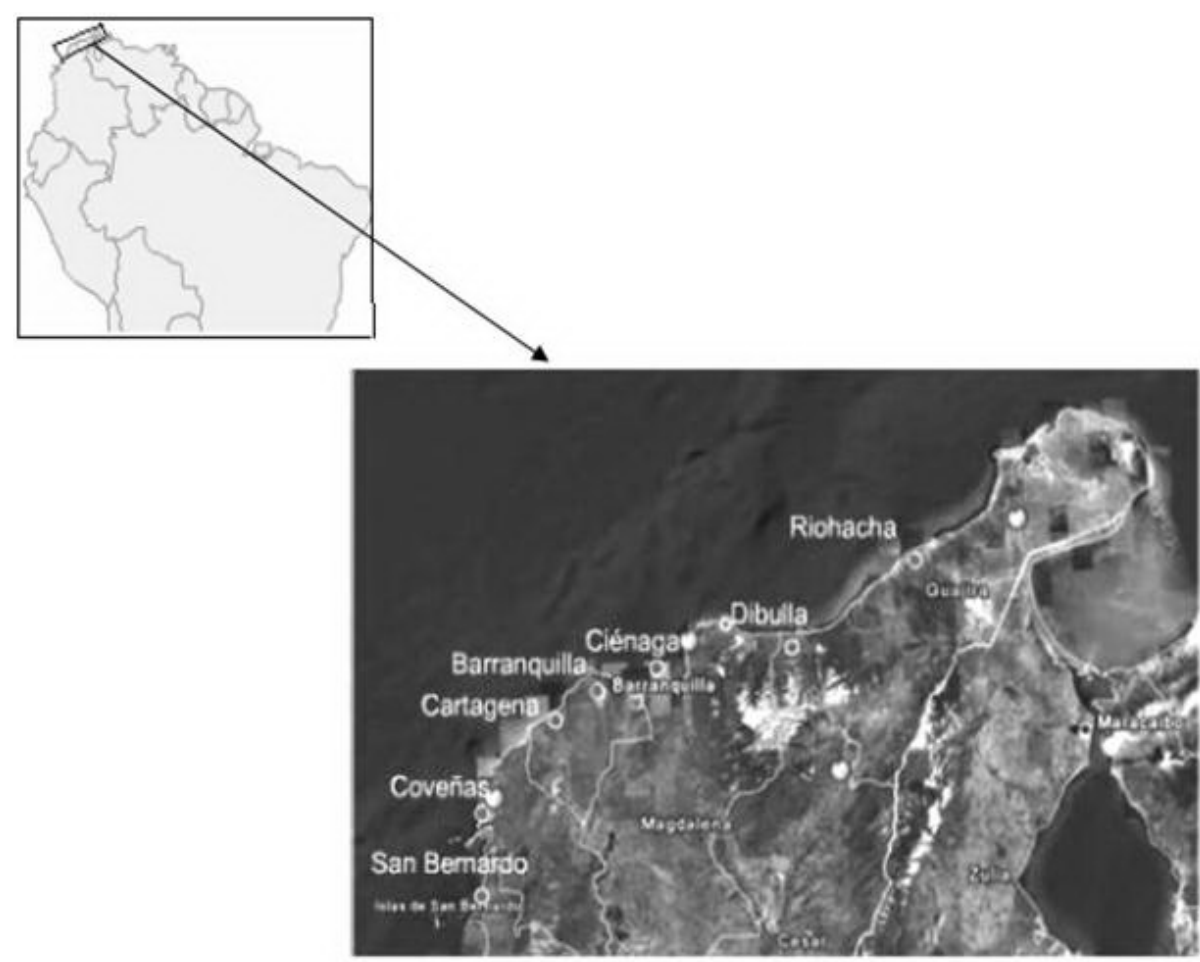

Figure 1. Collection sites for seven Ochlerotatus taeniorhynchus populations from Colombian Atlantic coast.

\section{Extraction and genotyping of microsatellites}

DNA isolation was based on the protocol described by Ravel et al. (2002), where DNA was extracted using the Chelex ${ }^{\circledR} 100$ reagent (Biorad, CA, USA), with slight modifications. Eight heterologous microsatellite loci were used: AEDGA, AED19F, AEDC1, and AEDS54 (Ravel et al., 2002), OchcA2, OchcB4, OchcB9, and OchcD11 (Porretta et al., 2005). The nucleotide sequences are shown in Table 1. Polymerase chain reaction was done with a total volume of $25 \mu \mathrm{L}$ for the final reaction containing $38 \mathrm{ng}$ template DNA, $1 \mathrm{X}$ buffer, $2.8 \mathrm{mM}$ $\mathrm{MgCl}_{2}, 0.2 \mathrm{mM}$ dNTP, 0.8 units Taq polymerase and $0.12 \mathrm{mM}$ of each primer. The annealing temperature was $54^{\circ} \mathrm{C}$. Polymerase chain reaction conditions were: 3 min at $93^{\circ} \mathrm{C}, 34$ cycles of $30 \mathrm{~s}$ at $94^{\circ} \mathrm{C}, 38 \mathrm{~s}$ at annealing temperature, $38 \mathrm{~s}$ at $72^{\circ} \mathrm{C}$, and final extension of $5 \mathrm{~min}$ at $72^{\circ} \mathrm{C}$. Products obtained in the amplification were examined on sequencing acrylamide-urea gels (7 M). An amount of $2.5 \mu \mathrm{L}$ amplified DNA was electrophoresed on $4 \%$ polyacrylamide denaturing gels in $1 \mathrm{X}$ TBE running buffer, at 85 watts for $3 \frac{1}{2} \mathrm{~h}$. Bands were examined on the gels after staining with silver nitrate (GenePrint STR Systems, Silver Stain Detection). The size of alleles was determined according to the separation pattern of molecular weight marker OX174 Hinf, which was simultaneously run with the samples of the seven populations of mosquitoes. 


\begin{tabular}{|c|c|c|c|c|c|c|}
\hline Locus & $\begin{array}{l}\text { Accession No. } \\
\text { in GenBank }\end{array}$ & Repeating motif & Primer sequence $\left(5^{\circ}-3^{\circ}\right)$ & $\begin{array}{l}\text { Temperature } \\
\qquad\left({ }^{\circ} \mathrm{C}\right)\end{array}$ & $\begin{array}{l}\text { No. of } \\
\text { alleles }\end{array}$ & $\begin{array}{l}\text { Size range } \\
\quad(\mathrm{bp})\end{array}$ \\
\hline AEDGA & U28803 & $(\mathrm{GAA})_{3}(\mathrm{GAC})_{4}(\mathrm{GAA})_{3}$ & $\begin{array}{l}\text { F: CCG AAG AAA TTG GGG TGA CC } \\
\text { R: CCT CTC GGT GTT CGC TAA CC }\end{array}$ & 55 & 3 & $139-151$ \\
\hline AED19F & U91680 & $(\mathrm{GGA})_{5}$ & $\begin{array}{l}\text { F: TTA TGG AAC TGG TAA GCCC } \\
\text { R: GTA TGA CAA CTC TGG AAT GG }\end{array}$ & 50 & - & - \\
\hline AEDC1 & U58313 & $(\mathrm{GTA})_{6}(\mathrm{ACG})(\mathrm{GTA})_{3}$ & $\begin{array}{l}\text { F: Ñ TGC AGG CCC AGA TGC ACA GCC } \\
\text { R: TCC GCT GCC GTT GGC GTG AAC }\end{array}$ & 50 & - & - \\
\hline AEDS54 & U28803 & $(\mathrm{GAA})_{3}(\mathrm{GAC})_{4}(\mathrm{GAA})_{3}$ & $\begin{array}{l}\text { F : AAT CTT CGC TCT GGC CGT CG } \\
\text { R: GGT TGG CAC CGC ACT TGG CG }\end{array}$ & 50 & - & - \\
\hline OchcA2 & AY677187 & $\begin{array}{l}(\mathrm{GT})_{6} \mathrm{TT}(\mathrm{TG})_{3} \mathrm{AGTA}(\mathrm{TG})_{2} \\
\text { TTTGTA(TG)})_{2}\end{array}$ & $\begin{array}{l}\text { F: ATC TAT TCC GTG CTG CTG CT } \\
\text { R: GCA AAC TAC CAC TCC GGA AC }\end{array}$ & 58 & 5 & $178-236$ \\
\hline OchcB4 & AY677191 & $\begin{array}{l}(\mathrm{GT})_{2} \mathrm{GG}(\mathrm{CA})_{2}(\mathrm{TG})_{2} \\
\mathrm{GAG}(\mathrm{CTT})_{2} \mathrm{TA}(\mathrm{CT})_{2} \\
\mathrm{AGGG}(\mathrm{CT})_{3} \mathrm{~A}(\mathrm{TG})_{4}\end{array}$ & $\begin{array}{l}\text { F: TCC GCT GAA GAG TTT TCC AT } \\
\text { R: GAC ATT CGA GAA AQCC TCC GA }\end{array}$ & 54 & 4 & $178-188$ \\
\hline OchcB9 & AY677194 & $\begin{array}{l}(\mathrm{CTA})_{4} \mathrm{CA}(\mathrm{TG})_{2} \\
(\mathrm{CTA})_{3} \mathrm{CTT}(\mathrm{CTA})_{3} \ldots \\
(\mathrm{CTA})_{3}(\mathrm{TGT})_{2}(\mathrm{TCA})_{1} \\
(\mathrm{TGT})_{2} \ldots(\mathrm{CAC})_{6}\end{array}$ & $\begin{array}{l}\text { F: CCA AAA CAC TCT GCA TCC AA } \\
\text { R: GGA CTG GCC GAA TAC AGA GA }\end{array}$ & 56 & 3 & $272-282$ \\
\hline OchcD11 & AY677195 & $\begin{array}{l}(\mathrm{GT})_{3} \mathrm{~A}(\mathrm{TG})_{5} \mathrm{TA}(\mathrm{TG})_{6} \\
\mathrm{TA}(\mathrm{TG})_{4}\end{array}$ & $\begin{array}{l}\text { F: TTC GAC TCA GTT CGA CGA GA } \\
\text { R: GGT CAA TTC GGT TGA GTG GTT }\end{array}$ & 55 & 4 & $137-141$ \\
\hline
\end{tabular}

\section{Population genetic analysis}

The first genetic variation parameters calculated for the seven populations of $O$. taeniorhynchus on the Colombian Atlantic coast were: proportion of polymorphic loci, number of alleles per locus and expected heterozygosity (Nei, 1973). Differences among the estimated values for these parameters were statistically analyzed by the Student $t$-test. In order to determine if the populations were in Hardy-Weinberg (HW) equilibrium, the correction between the observed and expected genotypic frequencies was done using the chi-square test. For processing these statistics, the GENEPOP, version 3.4, software was used (Raymond and Rousset, 1995). The linkage disequilibrium was determined by accurate tests on contingency tables, using the GENEPOP software.

The genetic structure was examined by means of $F$-statistics (Wright, 1951), according to the procedure by Weir and Cockerham (1984) and using the FSTAT software for calculations (Goudet, 2002). The standard deviations of $F$-statistics and the confidence intervals (95 and 99\%) were calculated with jackknifing and bootstrapping $(10,000)$ over loci, respectively. Fst significance (genetic heterogeneity) was calculated with the $\mathrm{G}$ test (10,000 randomizations of alleles, random mating assumed) and with log-likelihood $\mathrm{G}$ test (10,000 randomizations of genotypes, random mating not assumed) (Goudet et al., 1996). Fis and Fit significance was calculated in a similar way (10,000 randomizations of alleles within and overall for the samples analyzed). Estimation of indirect gene flow was obtained from Fst statistics, where Nm is the product of the effective population size and the migration rate per generation, assuming an infinite island model (Wright, 1965) where $\mathrm{Nm}=((1 /$ Fst $)-1) / 4$. 


\section{RESULTS}

\section{Genetic variability levels}

Three of the eight loci analyzed in the seven populations, AED19F, AEDS54, and AEDC1, did not show amplification, while the remaining five loci were polymorphic, thereby establishing a polymorphism rate of $62.5 \%$. The polymorphic loci and the number of alleles in each one of them were: AEDGA ( 3 alleles: 139, 147, and $151 \mathrm{bp}$ ), OchcB9 ( 3 alleles: 272, 280, and 282 bp), OchcB4 (4 alleles: 178, 182, 184, and 188 bp), OchcD11 (4 alleles: 135, 137, 140, and $141 \mathrm{bp}$ ), and OchcA2 (5 alleles: 178, 182, 188, 212, and $236 \mathrm{bp}$ ). Nineteen polymorphic bands were determined with an average of 3.8 alleles per locus. Finally, data of expected heterozygosity were in a range from 0.568 to 0.660 (Table 2).

\begin{tabular}{|c|c|c|c|c|c|c|c|}
\hline \multirow[t]{2}{*}{ Locus } & \multicolumn{7}{|c|}{ Population } \\
\hline & $\mathrm{SnB}$ & Cov & Car & Bqui & Cien & Dibu & Rioh \\
\hline \multicolumn{8}{|l|}{ AEDGA } \\
\hline Но & 0.166 & 0.066 & 0.333 & 0.133 & 0.600 & 0.566 & 0.533 \\
\hline $\mathrm{He}$ & 0.371 & 0.341 & 0.571 & 0.126 & 0.424 & 0.410 & 0.395 \\
\hline Fis & 0.551 & 0.804 & 0.416 & -0.054 & -0.414 & -0.381 & -0.348 \\
\hline $\mathrm{P}$ & 0.000 & 0.000 & 0.000 & 1.000 & 0.030 & 0.065 & 0.075 \\
\hline \multicolumn{8}{|l|}{ OchcA2 } \\
\hline Но & 0.766 & 0.466 & 0.800 & 0.866 & 0.800 & 0.500 & 0.633 \\
\hline $\mathrm{He}$ & 0.800 & 0.719 & 0.741 & 0.765 & 0.813 & 0.762 & 0.798 \\
\hline Fis & 0.042 & 0.351 & -0.079 & -0.132 & 0.016 & 0.343 & 0.207 \\
\hline$P$ & 0.000 & 0.000 & 0.000 & 0.000 & 0.000 & 0.000 & 0.000 \\
\hline \multicolumn{8}{|l|}{ OchcB4 } \\
\hline Но & 0.700 & 0.933 & 0.833 & 0.900 & 0.666 & 0.900 & 0.766 \\
\hline $\mathrm{He}$ & 0.733 & 0.675 & 0.704 & 0.698 & 0.641 & 0.651 & 0.725 \\
\hline Fis & 0.045 & -0.382 & -0.182 & -0.287 & -0.039 & -0.381 & -0.057 \\
\hline $\mathrm{P}$ & 0.000 & 0.000 & 0.000 & 0.000 & 0.000 & 0.000 & 0.000 \\
\hline \multicolumn{8}{|l|}{ OchcB9 } \\
\hline Но & 0.600 & 0.866 & 0.833 & 0.766 & 0.600 & 0.866 & 0.833 \\
\hline $\mathrm{He}$ & 0.672 & 0.612 & 0.632 & 0.660 & 0.672 & 0.612 & 0.632 \\
\hline Fis & 0.107 & -0.414 & -0.318 & -0.160 & -0.107 & 0.414 & -0.318 \\
\hline $\mathrm{P}$ & 0.000 & 0.000 & 0.000 & 0.000 & 0.000 & 0.000 & 0.000 \\
\hline \multicolumn{8}{|l|}{ OchcD11 } \\
\hline Но & 0.700 & 0.766 & 0.133 & 0.800 & 0.266 & 0.466 & 0.100 \\
\hline $\mathrm{He}$ & 0.639 & 0.551 & 0.650 & 0.590 & 0.489 & 0.458 & 0.577 \\
\hline Fis & -0.095 & -0.389 & 0.795 & -0.354 & 0.455 & -0.017 & 0.826 \\
\hline $\mathrm{P}$ & 0.000 & 0.000 & 0.000 & 0.000 & 0.000 & 0.004 & 0.000 \\
\hline $\begin{array}{l}\text { Mean He } \\
\text { (all loci) }\end{array}$ & 0.643 & 0.580 & 0.660 & 0.568 & 0.608 & 0.579 & 0.625 \\
\hline
\end{tabular}

$\mathrm{Ho}=$ observed heterozygosity; $\mathrm{He}=$ expected heterozygosity; Fis $=$ inbreeding coefficient; $\mathrm{P}=$ the probability for rejecting Hardy-Weinberg equilibrium $=$ significant $\mathrm{P}$ values $(<0.05) . \mathrm{Snb}=\mathrm{San}$ Bernardo; $\mathrm{Cov}=$ Coveñas; $\mathrm{Car}=$ Cartagena; Bqui $=$ Barranquilla; Cien $=$ Ciénaga; Dibu $=$ Dibulla; Rioh $=$ Riohacha .

\section{Hardy-Weinberg equilibrium}

Of the loci analyzed, $91.42 \%$ were in significant HW disequilibrium. Data obtained for each population, after the application of the chi-square test, indicated that San Ber- 
nardo del Viento deviated from HW equilibrium in all loci analyzed, four due to deficit of heterozygotes (AEDGA, OchcA2, OchcB4, and OchcB9; P = 0.0000) and one due to excess of heterozygotes (OchcD11; $\mathrm{P}=0.0000)$. Likewise, Coveñas showed HW deviation in all loci, two due to heterozygote deficits (AEDGA and OchcA2; $\mathrm{P}=0.0000$ ) and three due to heterozygote excess (OchcB4, OchcB9, and OchcD11; $\mathrm{P}=0.0000)$. Cartagena also had highly significant deviation from HW equilibrium: two due to heterozygote deficits (AEDGA and OchcD11; P = 0.0000) and three due to heterozygote excess (OchcA2, OchcB4, and OchcB9; $\mathrm{P}=0.0000)$. Barranquilla showed HW disequilibrium in four loci, all of them due to heterozygote excess (OchcA2, OchcB4, OchcB9, and OchcD11; P = 0.0000). Ciénaga had HW disequilibrium in five loci, three due to heterozygote deficits (OchcA2, OchcB9, and OchcD11; P = 0.0000) and two due to heterozygote excess (AEDGA and OchcB4; $\mathrm{P}=0.0000$ ). In addition, Dibulla had HW disequilibrium in four loci, two because of heterozygote deficits (OchcA2, OchcB9; $\mathrm{P}=0.0000)$ and two because of heterozygote excess $(\mathrm{OchcB} 4$ and OchcD11; $\mathrm{P}=0.0000)$. Finally, Riohacha showed HW disequilibrium in four loci, two due to heterozygote deficits (OchcA2 and OchcD11; P $=0.0000)$ and two due to heterozygote excess (OchcB4 and OchcB9; $\mathrm{P}=0.0000)$ (Table 2). Of the total loci in HW disequilibrium, $46.87 \%$ was due to heterozygote deficits and the remaining $53.13 \%$ occurred due to heterozygote excess.

On the other hand, there was no significant linkage disequilibrium among the different locus genotypes, suggesting the independence among loci.

\section{Population structure}

Wright's F-statistic values were determined (Fis, Fst, and Fit) for the five polymorphic markers. Genetic heterogeneity (Fst) reflected low levels of genetic differentiation among populations of $O$. taeniorhynchus on the Colombian Atlantic coast by configuring an average value of 0.0369 , without being statistically significant $(\mathrm{P}>0.05)$. This means that on average, each population studied has approximately $96 \%$ of the genetic variability found in the other populations. Individually, none of the loci had high Fst values. HW equilibrium deviation within the subpopulations showed, on average, a negative value of Fis, -0.0098 , reflecting a slight heterozygote excess without statistical significance $(\mathrm{P}=0.691)$. On the other hand, in the total population (Fit) HW equilibrium deviation showed heterozygote deficits with a value of 0.0275 , and as the previous one without any statistical significance $(\mathrm{P}=0.197)$ (Table 3$)$.

Table 3. Weir and Cockerham estimates of Wright's F-statistic values calculated at each locus for seven Ochlerotatus taeniorhynchus populations.

\begin{tabular}{lccc}
\hline Locus & Fis & Fst & Fit \\
\hline AEDGA & 0.0910 & $0.0652^{*}$ & 0.1502 \\
OchcA2 & $0.1052^{*}$ & 0.0327 & $0.1344^{*}$ \\
OchcB4 & -0.1800 & 0.0326 & -0.1415 \\
OchcB9 & -0.1938 & 0.0191 & -0.1711 \\
OchcD11 & $0.1830^{*}$ & $0.0480^{*}$ & $0.2222^{*}$ \\
Mean & -0.0098 & 0.0369 & 0.0275 \\
\hline
\end{tabular}

*Values differed significantly from zero. Fis = HW deviation within the subpopulations; Fst = genetic heterogeneity; Fit $=$ HW deviation in the total population. 
Based on Fst statistics, the gene flow (Nm) estimated for the seven populations studied was 6.52 individuals per generation, which is considered to be high and points to genetic homogeneity among the populations analyzed.

\section{DISCUSSION}

\section{Polymorphism, number of alleles per locus and genetic variability}

Since the present study lacked species-specific primers for $O$. taeniorhynchus, it was necessary to select the microsatellites from those derived from mosquitoes of the subfamily Culicinae, particularly of the species $A$. aegypti and $O$. caspius, developed by Ravel et al. (2002), and Porretta et al. (2005), respectively. The results showed that five loci were polymorphic, while the remaining three, AED19, AEDS54, and AEDC1, did not amplify. Of the four loci corresponding to A. aegypti that were evaluated, those that failed to amplify are part of this mosquito while just one of them was polymorphic. Besides, four of the polymorphic markers belong to the mosquito $O$. caspius, which belongs to the same genus as $O$. taeniorhynchus, and therefore, they are phylogenetically related, this being probably the main cause of the presence of the same markers in the two mosquitoes. However, it cannot be unequivocally discarded that the primers that were not amplified are not present in this species since some other variables in the flanking region could eventually affect the correct amplification (Ravel et al., 2002). Nevertheless, it is necessary to point out that the frequencies and types of microsatellites may vary widely in many species of arthropods (Chambers et al., 2007); for example, these markers have been found to be limited and insufficient in Culicinae mosquitoes, as detected in A. aegypti (Huber et al., 1999; Fagerberg et al., 2001), Culex pipiens (Keyghobadi et al., 2004; Smith et al., 2005), and C. pipiens quinquefasciatus (Fonseca et al., 1998). Based on this reasoning, it is probable that the loci that were not amplified in this study are not definitively present in $O$. taeniorhynchus.

The number of alleles per locus in the populations of $O$. taeniorhynchus analyzed had a range of 3 to 5 , being relatively low in comparison with other population genetic studies carried out in mosquitoes with microsatellite markers; thus, for example, Huber et al. (2002), established for $A$. aegypti a range of 4 to 12 alleles per locus; Scarpassa and Conn (2007) determined for $A$. darlingi a range of 5 to 25 alleles per locus; Mirabello et al. (2008) showed for different populations of $A$. darlingi from Peru and Brazil, ranges of 5 to 11 and 6 to 22 alleles per locus, respectively. However, ranges of allele numbers per locus have been established that are similar to that of the present study, as reported by Mirabello et al. (2008) using the same species but in other populations of the mosquito from Belize and Guatemala, where the range was 2 to 7 alleles per locus. However, even more similar is the number of alleles per locus reported by Porretta et al. (2005), where an average of 3.7 for $O$. caspius was obtained, very close to that established in the present study of $O$. taeniorhynchus, which was 3.8 alleles per locus, thus reflecting a similar behavior in this parameter of genetic variability for the genus Ochlerotatus. In this same tendency of differences and similarities with other studies using microsatellite markers in insects of the family Culicidae, a range of expected heterozygosity was determined between 0.568 and 0.660 for the populations of mosquitoes analyzed in the present study and considered to be slightly high compared with other works on mosquitoes (Ayala et al., 2006; Scarpassa and Conn, 2007; Moreno et al., 2007; Antonio-Nkondjio et al., 
2008). Moreover, the importance of the information on the value of expected heterozygosity should be noted in the analysis of genetic variability described here, as this parameter is not affected by sample size (De Sousa et al., 1996; Ruiz-García et al., 2003).

The results obtained among genotype pairs of the various polymorphic microsatellite loci showed that there was no significant linkage disequilibrium among loci, suggesting the independence of the loci used in this study, and therefore the absence of allele combinations among the chromosomes of the insect in the subpopulations analyzed. Thus, the information on genetic variability and heterogeneity obtained from each of the polymorphic markers used in this study is relevant.

In general, the values of genetic variability obtained in this study are very similar to those established in a previous one on $O$. taeniorhynchus populations, using isoenzyme markers, from the same Colombian region (Bello and Ruiz-García, 2009). However, it is probable that when species-specific microsatellite loci are used, polymorphism levels could be different and higher compared with the results obtained using isoenzyme markers, such as those reported by da Costa-Ribeiro et al. (2006), where microsatellite markers displayed higher polymorphism compared to isoenzyme loci established for $A$. aegypti populations from five districts in Rio de Janeiro.

\section{Hardy-Weinberg equilibrium}

The results show that all populations of mosquito O. taeniorhynchus in the Colombian Atlantic coast were in HW disequilibrium due to heterozygote deficit or excess, although slightly in favor of heterozygote genotypes. This situation was also reflected by the HW disequilibrium at the intrapopulation level, which had a small negative non-significant value (Fis $=-0.0098)$. On the other hand, at the level of the total population, a positive value was determined (Fit $=0.0275$ ), indicating HW disequilibrium due to heterozygote deficits, although it was not statistically significant. The general situation indicates that the HW disequilibrium in the populations of the species in the Colombian region analyzed is not evenly affected, in drastic terms, by heterozygote or homozygote genotypes (Ruíz-García et al., 2003, 2006).

However, at the individual level, HW disequilibrium was seen in the populations of San Bernardo del Viento and Ciénaga, mainly due to heterozygote deficits but not in all loci; this allows the inference of the existence of natural evolutionary events that influence this finding. Probably the population subdivision (Wahlund effect) would be the more consistent explanation of the former parameter since other causes such as endogamy, genetic drift and presence of null alleles, which can also explain those situations, are discarded as these conditions would affect any marker equally; this eventuality was not observed in these populations, where the presence of loci in HW disequilibrium occurred also due to heterozygote excess. The simultaneous existence of heterozygote deficit and excess, with dominance of deficits, in these populations is highly compatible with an effect of genetic subdivision present in some loci, but not necessarily in all of them.

On the contrary, in other mosquito populations where there was HW disequilibrium due to heterozygote excess, Coveñas, Cartagena and Barranquilla, gene migrations could have occurred in these neighboring populations in the order previously indicated, one after another and from west to east along the Colombian Atlantic coast, where this situation would eventually have an important homogenizing effect on the establishment of the above-mentioned 
disequilibrium. However, it is also possible that in the reproductive dynamics of the mosquito populations at these sites a crossing of different genotypes had occurred (not in a random way) with the consequences already indicated. This is explained when we observe that most of the loci that determined the HW disequilibrium due to heterozygote excess are practically the same in these three populations.

\section{Population structure}

The average of the total Fst index corresponded to a value of 0.0369 , which was not significant, indicating a low level of genetic differentiation of the mosquito among the populations analyzed in the selected Colombian regions. In comparing this heterogeneity value with other population genetic works carried out with microsatellite markers, where the same statistic was evaluated, for example in $A$. aegypti from five districts of Rio de Janeiro, a high and significant value of $0.3304, \mathrm{P}<0.05$, was obtained (da Costa-Ribeiro et al., 2006), indicating genetic differentiation among the populations analyzed. Likewise, in various species of Anopheles, high and significant ranges of Fst have been recorded among the mosquito populations (Moreno et al., 2007; Scarpassa and Conn, 2007; Mirabello et al., 2008), demonstrating in turn different degrees of genetic differentiation. Therefore, the high gene flow (Nm $=6.52$ ) in the present study, which indicates the number of migrants per generation among the sampled populations of $O$. taeniorhynchus on the Colombian Atlantic coast, suggests a homogenizing genetic effect among the insect populations, showing low structuration of the mosquito in the regions analyzed, which is in concordance with a characterization that may correspond to local populations of the same species in the indicated geographical area.

On the other hand, in the recent study by Bello and Ruiz-Garcia (2009) on the same species and in the same populations from the Colombian Atlantic coast, a small degree of genetic heterogeneity was detected but with high gene flow, which differs only by the lower levels of genetic heterogeneity found in the present study. Both studies coincide in that these mosquitoes show a high gene flow among the populations analyzed. In view of the absence of clear spatial patterns demonstrated in the previous study (Bello and Ruiz-Garcia, 2009) and the inferred genetic homogeneity among the populations analyzed here, it is suggested that this species could circulate along this region without restriction, transporting different VEEV immunological subtypes throughout the Caribbean coast.

In conclusion, the polymorphic microsatellite loci used in the present study are a useful molecular tool in the study of genetic variability and heterogeneity of the mosquito $O$. taeniorhynchus on the Colombian Atlantic coast, providing important data to be taken into account in control strategies for the populations of the insect in this vast geographical area of Colombia. Likewise, findings of this study are in agreement with most of the results of previous studies on O. taeniorhynchus populations from the same Colombian region carried out with isoenzyme markers.

\section{ACKNOWLEDGMENTS}

We would like to thank Lorena Quintero and Magda Gaviria for their technical assistance, and María Martínez for valuable comments. We are also grateful to the Universidad del Rosario and to the Universidad de La Salle for financial support. 


\section{REFERENCES}

Aitken TH, Downs WG and Shope RE (1977). Aedes aegypti strain fitness for yellow fever virus transmission. Am. J. Trop. Med. Hyg. 26: 985-989.

Antonio-Nkondjio C, Ndo C, Kengne P, Mukwaya L, et al. (2008). Population structure of the malaria vector Anopheles moucheti in the equatorial forest region of Africa. Malar. J. 7: 120.

Ayala D, Goff GL, Robert V, de Jong P, et al. (2006). Population structure of the malaria vector Anopheles funestus (Diptera: Culicidae) in Madagascar and Comoros. Acta Trop. 97: 292-300.

Bello F and Ruiz-Garcia M (2009). Isoenzyme polymorphism and genetic structure of Ochlerotatus taeniorhynchus (Diptera: Culicidae) in populations from the Colombian Atlantic Coast. Biochem. Genet. 47: 462-470.

Chambers EW, Meece JK, McGowan JA, Lovin DD, et al. (2007). Microsatellite isolation and linkage group identification in the yellow fever mosquito Aedes aegypti. J. Hered. 98: 202-210.

Craig GB and Hickey WA (1965). Genetics of Aedes aegypti. In: Genetics of Insect Vectors of Disease (Wrigth JW and Pal R, eds.). Elsevier, Amsterdam, 67-131.

da Costa-Ribeiro MC, Lourenco-de-Oliveira R and Failloux AB (2006). Higher genetic variation estimated by microsatellites compared to isoenzyme markers in Aedes aegypti from Rio de Janeiro. Mem. Inst. Oswaldo Cruz 101: 917-921.

De Sousa GB, Jimenez A, Blanco A and Gardenal CN (1996). Gene flow in Aedes albifasciatus (Diptera:Culicidae) from central Argentina. J. Med. Entomol. 33: 894-900.

De Sousa GB, Aviles G and Gardenal CN (2000). Allozymic polymorphism in Aedes aegypti populations from Argentina. J. Am. Mosq. Control Assoc. 16: 206-209.

Dickerman RW, Cupp EW, Groot H, Alarcon AM, et al. (1986). Venezuelan equine encephalitis virus activity in northern Colombia during April and May 1983. Bull. Pan Am. Health Organ. 20: 276-283.

Fagerberg AJ, Fulton RE and Black WC (2001). Microsatellite loci are not abundant in all arthropod genomes: analyses in the hard tick, Ixodes scapularis and the yellow fever mosquito, Aedes aegypti. Insect Mol. Biol. 10: 225-236.

Fonseca DM, Atkinson CT and Fleischer RC (1998). Microsatellite primers for Culex pipiens quinquefasciatus, the vector of avian malaria in Hawaii. Mol. Ecol. 7: 1617-1619.

Forattini OP (1965). Entomología Médica. Vol. 2. Editora da Universidad de São Paulo, São Paulo, 302-312.

Goudet J (2000). FSTAT, a program to estimate and test gene diversities and fixation indices (version 2.9.1). Institute of Ecology, University of Lausanne, Lausanne. Available at [http://www.unil.ch/izea/softwares/fstat.html].

Goudet J, Raymond M, de Meeus T and Rousset F (1996). Testing differentiation in diploid populations. Genetics 144: 1933-1940.

Hancock JM (1999). Microsatellites and other Simple Sequences: Genomic Context and Mutational Mechanism. In: Microsatellites: Evolution and Applications (Goldstein DB and Schlötterer C, eds.). Oxford University Press, New York, 1-9.

Hribar LJ, Vlach JJ, Demay DJ, Stark LM, et al. (2003). Mosquitoes infected with West Nile virus in the Florida Keys, Monroe County, Florida, USA. J. Med. Entomol. 40: 361-363.

Huber K, Mousson L, Rodhain F and Failloux AB (1999). Short report: microsatellite sequences as markers for population genetic studies of the mosquito Aedes aegypti, the vector of dengue viruses. Am. J. Trop. Med. Hyg. 61: 1001-1003.

Huber K, Le Loan L, Hoang TH, Ravel S, et al. (2002). Genetic differentiation of the dengue vector, Aedes aegypti (Ho Chi Minh City, Vietnam) using microsatellite markers. Mol. Ecol. 11: 1629-1635.

Keyghobadi N, Matrone MA, Ebel GD, Kramer LD, et al. (2004). Microsatellite loci from the northern house mosquito (Culex pipiens), a principal vector of West Nile virus in North America. Mol. Ecol. Notes 4: 20-22.

Manguin S, Fontenille D, Chandre F, Lochouarn L, et al. (1999). Anopheline population genetics. Bull. Soc. Pathol. Exot. 92: 229-235.

Mirabello L, Vineis JH, Yanoviak SP, Scarpassa VM, et al. (2008). Microsatellite data suggest significant population structure and differentiation within the malaria vector Anopheles darlingi in Central and South America. BMC Ecol. 8: 3.

Moreno M, Salgueiro P, Vicente JL, Cano J, et al. (2007). Genetic population structure of Anopheles gambiae in Equatorial Guine. Malar. J. 6: 137.

Nei M (1973). Analysis of gene diversity in subdivided populations. Proc. Natl. Acad. Sci. U. S. A. 70: 3321-3323.

Olano VA (1985). Hallazgo de Aedes taeniorhynchus (Wiedemann, 1821) en un lugar del Municipio de Ambalema, Departamento del Tolima (Colombia) (Diptera: Culicidae) [Findings of Aedes taeniorhynchus (Wiedemann, 1821) in a local of the municipality of Ambalema, Department of Tolima (Colombia) (Diptera: Culicidae)]. Biomédica 5: 26-28.

Ortiz DI and Weaver SC (2004). Susceptibility of Ochlerotatus taeniorhynchus (Diptera: Culicidae) to infection with epizootic (subtype IC) and enzootic (subtype ID) Venezuelan equine encephalitis viruses: evidence for epizootic strain adaptation. J. Med. Entomol. 41: 987-993.

Ortiz DI, Wozniak A, Tolson MW, Turner PE, et al. (2003). Isolation of EEE virus from Ochlerotatus taeniorhynchus and 
Culiseta melanura in coastal South Carolina. J. Am. Mosq. Control Assoc. 19: 33-38.

Porretta D, Bellini R and Urbanelli SC (2005). Characterization of microsatellite markers in the mosquito Ochlerotatus caspius (Diptera: Culicidae). Mol. Ecol. Notes 5: 48-50.

Ravel S, Herve JP, Diarrassouba S, Kone A, et al. (2002). Microsatellite markers for population genetic studies in Aedes aegypti (Diptera: Culicidae) from Cote d'Ivoire: evidence for a microgeographic genetic differentiation of mosquitoes from Bouake. Acta Trop. 82: 39-49.

Raymond M and Rousset F (1995). GENEPOP (version 1.2): population genetics software for exact tests and ecumenicism. J. Heredity 86: 248-249.

Rivas F, Diaz LA, Cardenas VM, Daza E, et al. (1997). Epidemic Venezuelan equine encephalitis in La Guajira, Colombia, 1995. J. Infect. Dis. 175: 828-832.

Ruiz-Garcia M, Ramirez D, Bello F and Alvarez D (2003). Psorophora columbiae and Psorophora toltecum (Diptera: Culicidae) Colombian populations cannot be differentiated by isoenzymes. Genet. Mol. Res. 2: 229-259.

Ruiz-Garcia M, Bello F, Ramirez D and Alvarez D (2006). Genetic structure of the genera Psorophora (Diptera: Culicidae) in Columbian and North American populations using isoenzymes and ITS2 sequences. Genetika 42: 921-935.

Scarpassa VM and Conn JE (2007). Population genetic structure of the major malaria vector Anopheles darlingi (Diptera: Culicidae) from the Brazilian Amazon, using microsatellite markers. Mem. Inst. Oswaldo Cruz 102: 319-327.

Schlotterer C (2000). Evolutionary dynamics of microsatellite DNA. Chromosoma 109: 365-371.

Smith LJ, Keyghobadi N, Matrone MA, Escher RL, et al. (2005). Cross-species comparison of microsatellite loci in the Culex pipiens complex and beyond. Mol. Ecol. Notes 5: 697-700.

Tabachnick WJ and Black IV WC (1996). Population genetics in vector biology. In: The Biology of Disease Vectors (Beaty BJ and Marquardt WC, eds). University of Colorado, Niwot, 417-437.

Weir BS and Cockerham CC (1984). Estimating F-statistics for the analysis of population structure. Evolution 38: 1358-1370.

Wright S (1951). The genetical structure of populations. Ann. Eugenics 15: 323-354.

Wright S (1965). The interpretation of population structure by F-statistics with special regard to systems of mating. Evolution 19: 395-420. 